\title{
Knowledge and Attitude towards Ionizing Radiation among Patients Attending the King Khalid Hospital Najran, Saudi Arabia
}

\author{
Mana Goblan Almatared ${ }^{1,2}$, Ali Mohammed Almansour ${ }^{3,4}$, Abdulrazak Eissa Alquidaihi, ${ }^{1,2}$ \\ Hakeem Olatunde Agbaje ${ }^{5}$, Ali Saleh Almutared ${ }^{2}$ \\ ${ }^{1}$ College of Public Health and Health Informatics, University of King Saud Bin Abdulaziz for Health Sciences, Riyadh, KSA \\ ${ }^{2}$ King Khalid Hospital, Najran, KSA \\ ${ }^{3}$ School of Medicine, University of Auckland, Auckland, New Zealand \\ ${ }^{4}$ Maternity \& Children Hospital, Najran, KSA \\ ${ }^{5}$ International Medical Complex, Najran, KSA \\ Email: amal1mg@yahoo.com, aalm826@auckland.ac.nz,arazak9979@hotmail.com, almutared@yahoo.com,kimex10@yahoo.com
}

How to cite this paper: Almatared, M.G., Almansour, A.M., Alquidaihi, A.E., Agbaje, H.O. and Almutared, A.S. (2017) Knowledge and Attitude towards Ionizing Radiation among Patients Attending the King Khalid Hospital Najran, Saudi Arabia. Journal of Biosciences and Medicines, 5, 75-85. https://doi.org/10.4236/jbm.2017.510008

Received: September 19, 2017

Accepted: October 27, 2017

Published: October 30, 2017

Copyright $\odot 2017$ by authors and Scientific Research Publishing Inc. This work is licensed under the Creative Commons Attribution International License (CC BY 4.0).

http://creativecommons.org/licenses/by/4.0/

\begin{abstract}
Background/Aims: The aim of this study was to evaluate and assess the knowledge and attitude to dose and associated risks caused by Ionizing Radiation (IR) procedures among patients. Methods: This was a cross-sectional study involving 375 consecutive patients, conducted over a period of 4 months from at the radiology unit of King Khalid Hospital in Najran for IR procedures using self-administered questionnaires that was developed and distributed with consents and instructions to the participants. Results: About three-quarter $(60 \%)$ of the patients reported not being worried to undergo radiological tests. The same proportion of the patients also would not have radiological tests if they can tolerate the disease. About half (50\%) of the respondents stated that they would not be satisfied if no further radiological tests were required and $52 \%$ did not think that radiological procedures can cause hazards and side effects to the body. Also, over half (53\%) of the patients reported not knowing that radiological tests can cause cancer; $48 \%$ would not repeat the radiological tests within six months; and about $69 \%$ did not know the importance of Radiology for diagnosis. Conclusion: There is relatively low knowledge and awareness of the risks associated with Ionizing Radiation among patients in the study population. Therefore, there is a need for educating the public and not only medical personnel, about radiation exposure and associated risks.
\end{abstract}

\section{Keywords}

Knowledge, Attitude, Ionizing, Radiation 


\section{Introduction}

With the broad usage of X-ray, the protection of staff is becoming of high importance. The complexity of medical procedures creates the need for education and training in radiation safety especially during procedures as well as for the wearing of protective gears or tools to help prevent the risks associated with radiation [1].

Ionizing Radiation (IR) is a non-invasive procedure being used to diagnose diseases, guide surgical procedures and it helps the treating physicians to assess and plan their therapeutic interventions through the use of different modalities such as X-ray, CT Scan and Mammography.

Wong et al. in their study assessing the knowledge and practice of radiological imaging among local physicians, radiologists and interns, reported that the perception was unsatisfactory and could imply a tendency to misuse radiation which could have deleterious effects [2].

Willoughby et al. in a study carried out in England also revealed that participants have an estimated lifetime risk of cancer associated with radiological tests and had evaluated the underestimation of risk of procedures under radiation especially in the primary care [3].

The populations most affected by Ionizing Radiation during procedures are the staff, the patients, and the general public. The doses are easily measured by Dosimetry mainly for the staff and the general public but for patients, it is not realistically possible to measure the dose directly [4]. The practice of untrained clinicians in radiological safety or Radiobiology uncovered the potential for injury. Thus, patient education on radiological safety can lead to protection from injury and future risk of cancer [5].

Specialists such as cardiologists, vascular surgeons, gastroenterologists, etc., are aware of the risks of the ionizing radiation specifically when performing an intravascular surgery. During such a procedure, both the specialists and the patients are at risk of ionizing radiation hence, monitoring the exposure is of high necessity [6].

Some medical procedures demand higher doses of radiation that are determined by various parameters on patient doses. The staff usage of Dosimetry has helped in determining the level of the exposure. A Previous study by Miller et al. showed [7] significant clinical radiation dose to the patient during most procedures.

Although several parallel studies have been published, there is a paucity of literature in this area of research in the Kingdom of Saudi Arabia, in particular Najran province where health education among the populace is rather low. However, there are a few studies in the rest of Arab nations. One of such studies showed that only $6.1 \%$ of the respondents were able to identify the As Low As Reasonably Achievable (ALARA) principle and as much as $98.2 \%$ did not know that there was no safe dose limit according to international recommendations. [8]. 
The aim of the study was to assess patients' knowledge and attitude of ionizing radiation among patients.

\section{Materials and Methods}

This was a cross-sectional study design, which involved three hundred seventy-five (375) consecutive patients attending the Medical Diagnostic Imaging (DMI) Department at King Khalid Hospital in Najran Province, Kingdom of Saudi Arabia for ionization radiological procedures. Ethical approval was obtained from the College of Public Health and Health Informatics Ethics Committee Ethics King Khalid Hospital, Najran. Written informed consent was obtained from each study participant prior to enrolment after duly explaining the objectives of the study.

The study was conducted over a period of 4 months at the Medical Imaging Department of King Khalid Hospital (500 beds capacity) in Najran, which is situated at the southern part of the Kingdom of Saudi Arabia. Najran province has a population of about $(350,000)$ with an annual birth rate of $(7500)$.

A Self-administered survey questionnaire that aims to assess the patients' knowledge and attitudes toward the risks of radiation was developed. The questionnaires were written both in Arabic and English languages (Appendix 1). Responses were recorded based on 5 items in the Likert scale: "Strongly disagree, Disagree, Neutral, Agree and Strongly agree" and were randomly distributed by the Picture Archiving and Communication System (PACS).

The sample size was calculated based on one month patients' visits that equal (6500) patients with marginal error (5\%), confidence interval level (95\%), and respondent distribution (50\%). The required sample size was 363 . In order to account for attrition, this was increased by 12 to give a total sample of 375 . The questionnaires were randomly selected using the randomization table for the Radiology reception at King Khalid Hospital. A self-addressed envelope with number was included to facilitate the easy return of the paper copy while a dedicated address was available for the return of the questionnaire for those who chose to complete it.

The validity of research questionnaire was determined by conceptual approach which was based on literature review reference. The questionnaires were tested prior to the study on fifty patients so as to help standardize for readability, reliability and validity, in order to gain an adequate set of questions to capture what the research has intended to capture. The questionnaires were administered by the surveyor face to face and individually with a small group of participants ( $10 \%$ of the sample size) to help determine the accuracy, the language and the legibility of the survey. Thirty-three of the participants were approached in order to adjust the questionnaires according to their comments.

The data was analysed using the Statistical Package for Social Sciences (SPSS) version 22.0. Descriptive statistical analysis was performed to examine the frequencies and percentages of questionnaire responses on knowledge and attitudes 
about the radiation.

\section{Results}

The study had a $100 \%$ response rate. Table 1 shows the distribution of study participants according to socio-demographic information. A total of 375 patients, 221 (58.9\%) males and 154 (41.1\%) females who required Ionizing Radiation procedures participated in the study after meeting the inclusion criteria. There were more male participants constituting about two-thirds of the study sample. The patients' ages ranged from $17-82$ years with a total mean of $29.58 \pm$ 10.09 years. The modal age group was the young adults with a total number of 191 participants, constituting $51.1 \%$ of the study sample. There was however, no

Table 1. Distribution of study participants according to socio-demographic information.

\begin{tabular}{|c|c|c|c|}
\hline Variable & $\begin{array}{c}\text { Male } \\
\text { N (\%) }\end{array}$ & $\begin{array}{c}\text { Female } \\
\text { N (\%) }\end{array}$ & $\begin{array}{r}\text { Total } \\
\text { N (\%) }\end{array}$ \\
\hline \multicolumn{4}{|l|}{ Age(years) } \\
\hline Teenager (After puberty but $<19$ years) & $16(4.3)$ & $20(5.3)$ & $36(9.6)$ \\
\hline Young adult (19-<25 years) & $111(29.7)$ & $80(21.4)$ & $191(51.1)$ \\
\hline Adult $(25-<40$ years $)$ & $53(14.2)$ & $40(10.7)$ & $93(24.9)$ \\
\hline Middle-age (40 - 60 years) & $34(9.1)$ & $13(3.5)$ & $47(12.6)$ \\
\hline Elderly (>60 years) & $6(1.6)$ & $1(0.3)$ & $7(1.9)$ \\
\hline Total & $220(58.8)$ & $154(41.2)$ & $374(100.0)$ \\
\hline \multicolumn{4}{|l|}{ Marital status } \\
\hline Single & $112(29.9)$ & $75(20.0)$ & $187(49.9)$ \\
\hline Married & $109(29.1)$ & $79(21.1)$ & $188(50.1)$ \\
\hline Total & $221(58.9)$ & $154(41.1)$ & $375(100.0)$ \\
\hline \multicolumn{4}{|l|}{ Nationality } \\
\hline Saudi & $185(49.3)$ & $132(35.2)$ & $317(84.5)$ \\
\hline Non-Saudi & $36(9.6)$ & $22(5.9)$ & $58(15.5)$ \\
\hline Total & $221(58.9)$ & $154(41.1)$ & $375(100)$ \\
\hline \multicolumn{4}{|l|}{ Work status } \\
\hline Employed & $140(37.3)$ & $48(12.8)$ & $188(50.1)$ \\
\hline Unemployed & $77(20.5)$ & $103(27.5)$ & $180(48.0)$ \\
\hline Invalid & $4(1.0)$ & $3(0.8)$ & $7(1.8)$ \\
\hline Total & $221(58.9)$ & $154(41.1)$ & $375(100.0)$ \\
\hline \multicolumn{4}{|l|}{ Educational Level } \\
\hline Elementary & $12(3.2)$ & $9(2.4)$ & $21(5.6)$ \\
\hline Primary & $17(4.5)$ & $13(3.5)$ & $30(8.0)$ \\
\hline Secondary & $84(22.4)$ & $80(21.3)$ & $164(43.7)$ \\
\hline Tertiary & $107(28.5)$ & $46(12.3)$ & $153(40.8)$ \\
\hline Never been to school & $1(0.3)$ & $6(1.6)$ & $7(1.9)$ \\
\hline Total & $221(58.9)$ & $154(41.1)$ & $375(100.0)$ \\
\hline
\end{tabular}


significant gender difference.

There was an equal number of participants in terms of marital status: $49.9 \%$ were single and $50 \%$ were married with majority being Saudi nationals (85\%) while only $15 \%$ were non-Saudi citizens. Also, the number of employed and unemployed patients was almost equal in number.

With regard to the educational level of the respondents, $44 \%$ were Secondary school students, followed by those from Tertiary school (41\%). The primary and elementary pupils had the least number of participants being $8 \%$ and $5.6 \%$ respectively. About 7 (1.9\%) of the respondents had never been to school.

- 1 missing participant data under the age section

The attitude of participants towards radiation is shown in Table 2. Almost two-thirds $(60 \%)$ of patients did not worry during radiological procedures while $28.5 \%$ or almost one-third of them had apprehension to undergoing radiological procedures. A large proportion of the respondents (66.1\%) would not undergo any radiological test if they can tolerate the disease while $21 \%$ agreed to have radiological tests even with the toleration of the disease. The other participants were indifferent to these questions.

Almost half of the patients (46\%), were not pleased if no further radiological test was done while about $33 \%$ were pleased and felt that they did not need further radiological tests. However, a relatively large proportion (20.5\%) was indifferent to having further investigations regardless of the diagnosis made.

While only a quarter $(25.1 \%)$ of the respondents felt the tests cause hazards and side effects, about the same number were indifferent. However, over half of the participants (52.0\%) disagreed to this statement.

Table 2. Attitude toward radiation.

\begin{tabular}{|c|c|c|c|}
\hline \multirow[b]{2}{*}{ Items } & \multicolumn{3}{|c|}{ Responses } \\
\hline & $\begin{array}{c}\text { Disagree } \\
\text { Frequency (\%) }\end{array}$ & $\begin{array}{c}\text { Neutral } \\
\text { Frequency (\%) }\end{array}$ & $\begin{array}{c}\text { Agree } \\
\text { Frequency (\%) }\end{array}$ \\
\hline $\begin{array}{l}\text { I worry a lot during radiological } \\
\text { test procedure }\end{array}$ & $226(60.3)$ & $42(11.2)$ & $107(28.5)$ \\
\hline $\begin{array}{l}\text { I would not do the radiological tests } \\
\text { if I can tolerate the disease }\end{array}$ & $248(66.1)$ & $48(12.8)$ & $79(21.0)$ \\
\hline $\begin{array}{l}\text { I'm pleased with the diagnosis } \\
\text { without needing further } \\
\text { investigation through } \\
\text { radiological tests. }\end{array}$ & $173(46.1)$ & $77(20.5)$ & $125(33.3))$ \\
\hline $\begin{array}{l}\text { I feel that radiology tests cause } \\
\text { hazards and side effects }\end{array}$ & $195(52.0)$ & $86(22.9)$ & $94(25.1)$ \\
\hline $\begin{array}{l}\text { Radiologists not staying in the same } \\
\text { room makes me feel worried } \\
\text { about the procedures }\end{array}$ & $172(45.9)$ & 89 (23.7) & $114(30.4)$ \\
\hline $\begin{array}{l}\text { The instruction given by the } \\
\text { radiologist makes me feel anxious }\end{array}$ & $163(43.5)$ & $56(14.9)$ & $156(41.6)$ \\
\hline
\end{tabular}


About $46 \%$ of the respondents would not worry about the radiological procedure if the radiologist is not in the room, while about $30 \%$ of them get worried in the absence of the radiologist in the room.

Patients that do not feel anxious after instructions have been given by the radiologists were about 163 (43.5\%) of the respondents whereas 156 (41.6\%) of them do get anxious after instructions have been given to them. About 56 (14.9) respondents were neutral about this. This is also depicted in Figure 1.

Table 3 and Figure 2 shows the knowledge of respondents towards radiation procedures. More than half of the respondents (53.1\%) disagree that radiological tests can cause cancer and about a quarter of the respondents (25\%) believe that radiology can cause cancer. Over a fifth $(22.1 \%)$ didn't have an idea about the cancer risks associated with radiation.

Almost half of the patients $(48.3 \%)$ disagreed that repeating the radiological tests within six months knowing can cause harm to the body, while equal number of the participants $(25.9 \%$ each) either believed that repeating the radiological tests within that time could be deleterious to health or were neutral about it.

Those who do not know that radiation stays in their bones and tissues for longer periods correspond to $40 \%$ of the respondents while $36 \%$ of them believe that radiation stays in their bones and tissues for a longer period of time. Almost a quarter (24.3\%) however, was neutral about the question.

Sixty-nine percent (69\%), which represent more than two-thirds of the res-

\section{Attitude toward Radiation}

I worry a lot during radiological test procedure

I would not do the radiological tests if I can tolerate the disease

I'm pleased with the diagnosis without needing further investigation through radiological tests.

I feel that radiology tests cause hazards and side effects

Radiologists not staying in the same room makes me feel worried about the procedures

The instruction given by the radiologist makes me feel anxious

घResponses Disagree Frequency (\%) घResponses Neutral Frequency (\%) घ Responses Agree Frequency (\%)

Figure 1. Attitude towards radiation. 
Table 3. Knowledge toward radiation.

\begin{tabular}{cccc}
\hline & & Responses & \\
\cline { 2 - 3 } Items & $\begin{array}{c}\text { Disagree } \\
\text { Frequency (\%) }\end{array}$ & $\begin{array}{c}\text { Neutral } \\
\text { Frequency (\%) }\end{array}$ & $\begin{array}{c}\text { Agree } \\
\text { Frequency (\%) }\end{array}$ \\
\hline $\begin{array}{c}\text { I know that radiological tests can cause cancer } \\
\text { Repeating the radiological tests within six } \\
\text { months can cause harm to the body }\end{array}$ & $199(53.1)$ & $83(22.1)$ & $93(24.8)$ \\
$\begin{array}{l}\text { I know that the x-rays I received stay in my } \\
\text { bones and tissues for a long period }\end{array}$ & $181(48.3)$ & $91(24.3)$ & $134(35.7)$ \\
I know the importance of radiology for diagnosis & $150(40.0)$ & $49(13.1)$ & $68(18.1)$ \\
I know the difference among the different radiological tests & $257(68.5)$ & $49(13.1)$ & $135(36.0)$ \\
\hline
\end{tabular}

\section{Knowledge about radiation}

I know that radiological tests can cause cancer

\begin{tabular}{|l|l|l|}
\hline $53.1 \%$ & $22.1 \%$ & $24.8 \%$ \\
\hline
\end{tabular}

Repeating the radiological tests within six months can cause harm to the body

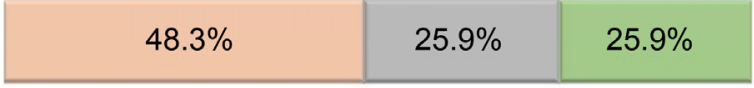

I know that the $\mathrm{x}$-rays I received stay in my bones and tissues for a long period

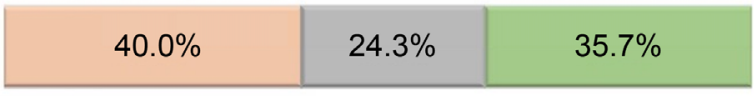

I know the importance of radiology for diagnosis

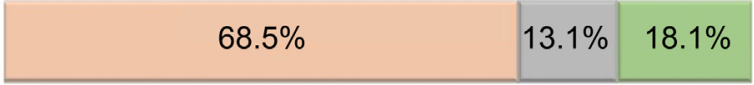

I know the difference among the different radiological tests

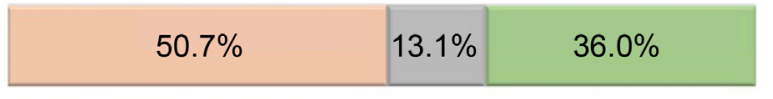

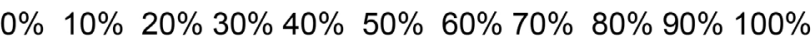

घResponses Disagree Frequency (\%) $\quad$ Responses Neutral Frequency (\%) $\quad$ Responses Agree Frequency (\%)

Figure 2. Knowledge towards radiation.

pondents do not know the importance of Radiology for diagnosis and only $18 \%$ of them are fully aware of the importance of Radiology in the identification of diseases.

About half of the respondents (50.7\%) do not know the difference among the various radiological tests but $36 \%$ or one-third of them are able to distinguish each radiological test.

\section{Discussion}

The use of radiation has become an essential diagnostic and therapeutic tool in modern medical practice. However, it poses some potential health risks. This in- 
stitution-based cross-sectional study was designed to assess the knowledge and attitude of patients toward Ionizing Radiation (IR) and the risks associated with repeated exposure to radiation due to the misuse or exposure to high doses. According to the findings from this survey, radiation knowledge awareness is generally inadequate in patients.

As with similar studies [9] [10] [11] [12] [13], the response rate was high as respondents willingly participated. This suggests the readiness of patients to learn more about radiation use and precautions needed to be taken.

Most of the patients who participated were Saudi Nationals who belong to the teenage or young adult group (18 - 28 years old) in the Secondary and Tertiary educational levels. The disparity may be due to the fact that other Nationals do not have access to free healthcare and wouldn't attend a government-based healthcare facility. Also, the demographic data showed that the percentage of respondents in terms of employment status, gender and marital status was equal as to the risk of exposure to radiations.

\subsection{Attitude toward Radiation}

Our survey revealed that over half of the patients felt that radiological tests pose no hazards or side effects. As a result, only about a third worry during radiological test procedures and about a fifth of the respondents would tolerate the disease rather than have the radiological tests. This may be due to the lack of orientation and information about the diagnostic procedure that will be performed. This clearly depicts the poor awareness level of the study population.

However, almost half of the patients felt radiological tests were still necessary regardless of the clinical diagnosis made. This could be due to the fact that healthcare needs are not on a fee-for-service basis for Saudi nationals and patients wouldn't mind having all prescribed tests including radiological.

About a third of the participants in our study affirmed they become worried when the Radiologists leave the room during the procedures. It is imperative to give thorough education to patients and explain to them that the reason the technologist leaves the room during the exposure is that the technologist would be exposed many times a day. Also, the instructions given by the Radiologist make many of the patients anxious.

\subsection{Knowledge about the Radiation}

It is somewhat alarming that majority of the patients in the study population are not fully aware of the risks associated with radiation. Also, it was revealed that over half of the respondents did not know that radiological tests can cause cancer as compared to the quarter that believes they can. This still bothers on the poor awareness level of the study population. Berrington de Gonzalez in his study estimated the risk of cancer due to diagnostic x-rays in the UK and the USA as 500 and 5700 deaths per year, respectively [14]. This is even more important for children as their tissues are more radiosensitive and they have longer 
lifespans [15].

In reply to questions asking if repeating the radiological tests within six months is harmful to the body, almost half (48\%) of the patients disagreed while only a little of a quarter (25.9) agreed that it can be harmful. This suggests that if patients are properly oriented about the risks or dangers associated with radiation such as the incidence of cancer, they will avoid undergoing repeated such tests. Also, about $40 \%$ of those surveyed disagree that radiation stays in their bones and tissues for longer periods while only $36 \%$ of them are aware of this fact.

The most staggering finding of this study is that a large number (69\%) compared to only $18 \%$ of the respondents do not know the importance of Radiology for diagnosis, which reflects on the lack of patient education in the clinics on the part of the physicians about the risks associated with radiation. However, over one-half (51\%) as against $36 \%$ of the respondents can distinguish the differences among the various radiological tests, but not the risks associated with these tests.

The mass education of the public about the benefits and hazards of radiological testing in the treatment of diseases might bring more reassurance to patients and assist them in making appropriate decisions when needed. The support and proper briefing from health care providers (physicians, technicians and radiographers) prior to any radiological test influence the patients' judgment and decision toward the diagnostic imaging. This in turn signifies the level of awareness and safety practices in the hospital about the use of radiation and even the misuse or overuse of radiation that could lead to the incidence of cancer.

\subsection{Limitations of the Study}

Even with the achievement of the study objective, a general assumption cannot be made until a larger representation of patients in Saudi Arabia is surveyed. Also, because the sample population is from a public healthcare institution, this may not take into account the attitude and knowledge of non-nationals who attend private health facilities. However, this preliminary study is one of its kinds in the region. Therefore, a follow-up study is warranted to reveal the current situation.

\section{Conclusions}

Knowledge of radiation/radiological tests is poor among patients. Awareness of the benefits and risks associated with radiation should be thoroughly explained to patients who require these tests in form of pep talks in the waiting areas. Continuous education programmes should be held for personnel.

In order to achieve radiation protection in diagnosis and treatment, health personnel must ensure the effective dose, which is not harmful to the tissues and organs, is administered.

\section{References}

[1] Le Heron, J., Padovani, R., Smith, I. and Czarwinski, R. (2010) Radiation Protection 
of Medical Staff. European Journal of Radiology, 76, 20-23. https://doi.org/10.1016/j.ejrad.2010.06.034

[2] Wong, C.S., Huang, B., Sin, H.K., et al. (2012) A Questionnaire Study Assessing Local Physicians, Radiologists and Interns' Knowledge and Practice Pertaining to Radiation Exposure Related to Radiological Imaging. European Journal of Radiology, 81, e264-268. https://doi.org/10.1016/j.ejrad.2011.02.022

[3] Willoughby, H., Ahmed, H., Jenkinson, R. and Edwards, A. (2013) GP Speciality trainees' Knowledge, Attitude and Practice Regarding Risks Associated with Common Radiological Investigations. Education for Primary Care, 24, 355-362. https://doi.org/10.1080/14739879.2013.11494200

[4] Pitcher, C.D. and Melanson, M.A. (2010) The Impact of Peer-Based Training on Reducing Radiation Doses from X-Ray Operations in an Interventional Pain Management Clinic. U.S. Army Medical Department Journal, 43-47.

[5] Valentin, J. (2000) Avoidance of Radiation Injuries from Medical Interventional Procedures. Annals of the ICRP, 30, 7-67. https://doi.org/10.1016/S0146-6453(00)00026-9

[6] Staniszewska, M.A. and Jankowski, J. (2000) Personnel Exposure during Interventional Radiologic Procedures. Med Pr, 51, 563-571.

[7] Miller, D.L., Balter, S., Cole, P.E., et al. (2003) Radiation Doses in Interventional Radiology Procedures: The RAD-IR Study: Part I: Overall Measures of Dose. Journal of Vascular and Interventional Radiology, 14, 711-727. https://doi.org/10.1097/01.RVI.0000079980.80153.4B

[8] Hamarsheh, A. and Ahmead, M. (2012) Assessment of Physicians' Knowledge and Awareness about the Hazards of Radiological Examinations on the Health of Their Patients. Eastern Mediterranean Health Journal, 18, 875-881.

[9] Evans, K.M., Bodmer, J., Edwards, B., et al. (2015) An Exploratory Analysis of Public Awareness and Perception of Ionizing Radiation and Guide to Public Health Practice in Vermont. Journal of Environmental and Public Health, 2015, Article ID: 476495. https://doi.org/10.1155/2015/476495

[10] Freudenberg, L.S. and Beyer, T. (2011) Subjective Perception of Radiation Risk. Journal of Nuclear Medicine, 52, 29s-35s. https://doi.org/10.2967/jnumed.110.085720

[11] Asefa, G., Getnet, W. and Tewelde, T. (2016) Knowledge about Radiation Related Health Hazards and Protective Measures among Patients Waiting for Radiologic Imaging in Jimma University Hospital, Southwest Ethiopia. Ethiopian Journal of Health Sciences, 26, 227-236. https://doi.org/10.4314/ejhs.v26i3.5

[12] Ricketts, M.L., Baerlocher, M.O., Asch, M.R. and Myers, A. (2013) Perception of Radiation Exposure and Risk among Patients, Medical Students, and Referring Physicians at a Tertiary Care Community Hospital. Canadian Association of Radiologists Journal, 64, 208-212. https://doi.org/10.1016/j.carj.2012.05.002

[13] Zwank, M.D., Leow, M. and Anderson, C.P. (2014) Emergency Department Patient Knowledge and Physician Communication Regarding CT Scans. Emergency Medicine Journal, 31, 824-826. https://doi.org/10.1136/emermed-2012-202294

[14] Berrington de Gonzalez, A. and Darby, S. (2004) Risk of Cancer from Diagnostic X-Rays: Estimates for the UK and 14 Other Countries. Lancet, 363, 345-351. https://doi.org/10.1016/S0140-6736(04)15433-0

[15] Heyer, C.M., Hansmann, J., Peters, S.A. and Lemburg, S.P. (2010) Paediatrician Awareness of Radiation Dose and Inherent Risks in Chest Imaging Studies-A Questionnaire Study. European Journal of Radiology, 76, 288-293.

https://doi.org/10.1016/j.ejrad.2009.06.014 


\section{Appendix 1: Questionnaire}

\section{Questionnaire}

Study Title: Knowledge and attitude toward ionization radiation among patients attending the MDI department at King Khalid Hospital, Najran

\section{SECTION A: Socio-demographic information}

A1. What is your Gender?

$\square$ Female $\quad$ Male

A2. How old are you?

A3. What is your Nationality?

A4. What is your marital status?

$\square$ Single $\quad$ Married

A5. Are you employed?

$\square$ Yes $\square$ No

A6. What is your education level?

$\square$ Elementary

$\square$ Primary

$\square$ Secondary

$\square$ Tertiary

$\square$ Never been to School

SECTION B: Attitude toward Radiation

\begin{tabular}{|c|c|c|c|c|c|}
\hline & $\begin{array}{l}\text { Strongly } \\
\text { disagree }\end{array}$ & disagree & Neutral & agree & $\begin{array}{c}\text { Strongly } \\
\text { agree }\end{array}$ \\
\hline B1. I worry a lot during radiological tests procedure & o & 0 & 0 & $\mathrm{o}$ & o \\
\hline B2. I would not do the radiological tests if I can tolerate the disease & 0 & 0 & 0 & 0 & 0 \\
\hline B3.I'm pleased with the diagnosis without needing further investigation through radiological tests. & $\circ$ & 0 & $\circ$ & $\circ$ & $\circ$ \\
\hline B4. I feel that radiological tests cause hazards and side effects & 요 & o & o & $\mathrm{o}$ & $\mathrm{O}$ \\
\hline B5. Radiologists not staying in the same room makes me feel worried about the procedures. & $\mathrm{o}$ & 0 & $\mathrm{o}$ & $\mathrm{o}$ & 0 \\
\hline B6.The instructions given by the radiologist makes me feel anxious & 0 & 0 & 0 & 0 & 0 \\
\hline
\end{tabular}

SECTION C: Knowledge about Radiation
\begin{tabular}{|l|c|c|c|c|c|}
\hline & $\begin{array}{l}\text { Strongly } \\
\text { disagree }\end{array}$ & disagree & Neutral & $\begin{array}{l}\text { Agree } \\
\text { Strongly } \\
\text { ggree }\end{array}$ \\
\hline C1. I know that radiological tests can cause cancer & 0 & 0 & 0 & 0 & 0 \\
\hline C2. Repeating the radiological tests within six months can cause harm to the body & $\circ$ & $\circ$ & $\circ$ & $\circ$ & $\circ$ \\
\hline C3. I know that the rays I received stays in my bones and tissues for long period & 0 & $\circ$ & 0 & 0 & $\circ$ \\
\hline C4. I know the importance of radiology for diagnosis & $\circ$ & $\circ$ & $\circ$ & $\circ$ & $\circ$ \\
\hline C5-I know the difference between different radiological tests & $\circ$ & $\circ$ & $\circ$ & $\circ$ & $\circ$ \\
\hline
\end{tabular}

